\title{
Therapeutic Effects of Ozone Therapy that Justifies Its Use for the Treatment of COVID-19
}

\author{
Silvia Menendez-Ceperd*, José Antonio Marques-Magallanes-Regojo ${ }^{2}$, Alberto Hernandez-Martinez ${ }^{3}$, Francisco Javier Hidalgo Tallón ${ }^{4}$ \\ and José Baeza-Noci ${ }^{5}$ \\ ${ }^{1}$ Scientific Advisor, 1350 Asturia Ave. Coral Gables,33134-Florida, USA \\ ${ }^{2}$ Claro Clinic, C/Policarpo Sanz 9, 1b, 36202 - Vigo, Spain \\ ${ }^{3}$ Department of Anesthesiology and Reanimation, Nuestra Señora del Rosario Hospital, Via Romana, s/n, 07800, Ibiza, Spain \\ ${ }^{4}$ Chair of Ozone Therapy and Chronic Pain, San Antonio de Murcia Catholic University, Spain \\ ${ }^{5}$ School of Medicine and Surgery, Valencia University, Spain
}

${ }^{\star}$ Corresponding author: Silvia Menendez-Cepero, Scientific Advisor, 1350 Asturia Ave. Coral Gables, 33134-Florida, USA; Tel: +1 786 626 3684; E-mail: silvana30102005@yahoo.es

Received: August 01, 2020; Accepted: August 05, 2020; Published: August 12, 2020

\begin{abstract}
SARS-Cov2, the virus causing COVID-19, is distributed globally since December 2019, causing a pandemic and there are currently no specific treatments available. Patients evolve differently and extreme cases have fatal outcomes after 10 days of being infected. The virus is known to cause Acute Respiratory Distress Syndrome (ARDS). Cytokine storm is considered to be one of the major causes of ARDS and multiple-organ failure. Due to the high lethality of SARS-CoV2 infections and its economic and social impact, it is necessary to seek new therapeutic procedures. It has been demonstrated that ozone therapy produces a significant improvement in blood flow and oxygenation of ischemic tissues. Also, ozone can achieve an equilibrium between Nrf2 and NF- $\mathrm{KB}$ factors, modulating the oxidative stress and the expression of pro-inflammatory cytokines. In clinical studies, ozone has a significant role in the treatment of pulmonary and vascular diseases. Today, ozone therapy represents the most practical approach for integrating standard therapies to achieve homeostasis. Therefore, due to the ozone therapeutical effects, it can be proposed as an adjunct therapy in SARS-CoV-2. Three randomized control trials (NCT04359303, NCT04370223 and NCT04444531) are pending classification and approval to start in Spain, one in Iran (IRCT20190618043923N4) and two more (NCT04366089 and NCT04388514) started in Italy one month ago.
\end{abstract}

Keywords: COVID-19, Immunomodulation, NF- $\mathrm{B}$, Nrf2, Oxidative stress, Ozone therapy

\section{Introduction}

According to the World Health Organization (WHO), viral diseases continue to emerge and represent a serious issue to public health. An epidemic of cases with unexplained low respiratory infections was first reported to the WHO Country Office in China, on December 31, 2019. The new virus was called SARS-CoV-2 and the disease cause was a "COVID-19" an acronym of "coronavirus disease 2019" [1]. Many of these patients deteriorated rapidly and required intubation and mechanical ventilation. Mortality rates are assumed to be around $3.7 \%$. There is currently no effective treatment $[2,3]$. The therapeutic strategies to deal with the infection are only supportive. Prevention, aimed at reducing transmission rates within the community is our best weapon.

COVID-19 has characteristics of two known syndromes [4,5]:

- Macrophage activation syndrome [6]: a life-threatening complication characterized by hypercytokinemia (cytokine storm) with multi-organ failure. It is characterized by an uncontrolled activation and proliferation of $\mathrm{T}$ lymphocytes and macrophages, producing extensive tissue damage as endothelial lesions that lead to the production of microthrombi. Laboratory abnormalities include a decrease in white blood cells, platelet and hemoglobin. There is a production of a high level of transaminase, a marked increase in ferritin, and evidence for intravascular coagulation activation. The protagonist of this storm is mainly interleukin 6 (IL-6) which promotes the differentiation of B lymphocytes. The cytokine storm also stimulates the production of acute-phase proteins and further plays a role in thermoregulation, bone maintenance and the function of the central nervous system. During inflammatory diseases, infections, autoimmune disorders, cardiovascular diseases and some types of cancer, there is an increase in IL-6.

- Antiphospholipid syndrome [7]: it is an autoimmune system disorder that manifests clinically as recurrent venous or arterial thrombosis. This also alters the homeostatic regulation of blood coagulation. The D-dimer is elevated in most patients with pneumonia and other indicators of coagulation are abnormal. Thrombocytopenia is also observed, which seems to be associated with a poorer prognosis. Analytically, the presence of high levels of ferritin in the blood is striking. They appear to respond to an acute inflammatory process. Liver enzymes also tend to be elevated. The $\mathrm{Fe}^{2+}$ released into 
the blood, in the presence of hydrogen peroxide produces hydroxyl radicals (Fenton reaction). This is extremely toxic, causing oxidative damage, mainly pulmonary, but also systemic. The lung tissue damage stimulates the monocyte-macrophage system which contributes significantly to the inflammatory process. Taking into account all the ozone therapeutical properties, which will be explained below, it can be proposed as an adjunct therapy for patients with COVID-19.

\section{Ozone Therapy and its Mechanism of Action}

Ozone $\left(\mathrm{O}_{3}\right)$ is an allotropic form of the element oxygen, containing one more atom than atmospheric oxygen. It is particularly unstable and decomposes spontaneously into diatomic oxygen, which, in practice, makes it very difficult to transport and store. Ozone therapy has been used for therapeutic purposes since the beginning of the last century and its use is increasingly demanded nowadays. It is characterized by the simplicity of its application, its great effectiveness and with good tolerance. International reports of adverse reactions to the application of ozone therapy place it among the lowest incidences with $0.0007 \%$ $[8,9]$. Ozone, at therapeutic doses, is capable of producing a small, transitory and controlled oxidative stress that stimulates a group of depressed biological functions without causing any adverse effect. This ozone's preconditioning effect is capable of rebalancing the upset redox state in the organism [10]. Biochemically, when blood is exposed to ozone for several minutes, it reacts immediately with different molecules present in biological fluids, namely antioxidants, proteins, carbohydrates and, preferentially, polyunsaturated fatty acids (Criegee reaction), leading to the formation of alpha-hydroxyhydroperoxides, hydrogen peroxide, ozonides and aldehydes such as 4-hydroxynonenal. These are important signaling molecules, with crucial roles modulating inflammation, cell proliferation, cell growth and cell death [11].

These alkenals can activate a nuclear transcriptional factor, called nuclear factor erythroid 2-related factor 2 (Nrf2) present in the cell cytoplasm bound to Keap-1 protein. Such a protein has -NH2 and, mainly, -SH groups (Cys273 and Cys288) which, by binding alkenals [for example 4-hydroxynonenal (4-HNE)] at picomolar levels, causes a conformational change favoring the dissociation of Nrf2. This is then imported into the nucleus where, after forming a heterodimer with Maf (musculoaponeurotic fibrosarcoma) protein, interacts with the Antioxidant Response Element (ARE) on DNA. Consequently, the synthesis of several antioxidative enzymes (superoxide dismutase, catalase, glutathione reductase, glutathione S-transferases, NADPHquinone oxidoreductase, heat shock protein 70 , phase II enzymes and Heme-oxygenase-1) are upregulated in various organs [12]. Also, reduces iron overload, and subsequent oxidative stress that is induced by elevated ferritin [13]. The increase of antioxidant capacity is the crucial step to counteract the chronic inflammation typical of diseases aggravated by chronic oxidative stress. An improvement of the antioxidant response has been reported in patients with asthma and Chronic Obstructive Pulmonary Disease (COPD), as emphysema, treated with ozone therapy [14-16]. Specifically, improvements were seen in IgE levels, inflammatory response, respiratory tests and clinical status. Also, in patients with rheumatoid arthritis, ozone has exerted beneficial effects $[17,18]$.

This ozone efficacy not only may be explained through its actions on cytokine control (diminished IL-1, IL-6 and tumor necrosis factor $\alpha-\mathrm{TNF} \alpha$ ) but also can reestablish cellular redox balance. It is known that reactive oxygen species can function as a second messenger to activate the nuclear transcription factor NF- $\mathrm{BB}$, which orchestrates the expression of a spectrum of genes involved in the inflammatory response. Nrf2 is able to modulate inflammation through multiple mechanisms, such as the regulation of redox homeostasis and the suppression of pro-inflammatory genes, either directly or through the interaction with NF-kB [19]. Inflammation increases local and systemic Reactive Oxygen Species (ROS) level while ROS enhance inflammation. The Nrf2-mediated ROS-homeostatic control can break this vicious cycle. Nrf2 reduces inflammation by preventing the recruitment of RNA polymerase II to start gene transcription of pro-inflammatory cytokines IL-6 and IL-1 $\beta$ [20]. The capability of Nrf2 to maintain redox homeostasis would prevent DNA damage, preserve proteostasis, and improve mitochondrial function while suppressing acute and chronic inflammation [20]. The antioxidant and anti-inflammatory effects of ozone involve activation of Nrf2, which is thus considered as a key factor for the efficacy of ozone treatments. A previous study reported that ozone preconditioning significantly reduced NF- $\mathrm{\kappa B}$ expression and inhibited inflammatory responses in liver ischemia/reperfusion injury [21]. Ozone can achieve an equilibrium between Nrf2 and NF$\kappa \mathrm{B}$, modulating the expression of pro-inflammatory cytokines with an important effect in cytoprotection (Figure 1) [20].

Besides, Nrf2-activator may attenuate the Toll-Like Receptor (TLR) mediated aberrant inflammation by activation of intrinsic cytoprotective proteins and suppression of pro-inflammatory mediators. Hence, these two major signaling pathways may interact differentially and their cross-talk can be manipulated to regulate inflammation [22]. TLR activation is critical in the initiation of an inflammatory response against pathogens by triggering the production of inflammatory cytokines, enhancing adaptive immunity [23]. Simultaneously, a negative feedback mechanism also exists that could prevent the over-activation of TLR signaling that may otherwise result in chronic inflammation or autoimmunity. Nrf2 activation interferes with the expression of pro-inflammatory proteins and suppresses inflammation. The interaction of TLR and Nrf2 helps in the regulation of the inflammation process. The linkage between TLR signaling and Nrf2-Keap1 pathway may serve as a bridge between immune regulation and oxidative stress responses through the regulation of inflammation [22]. It has been demonstrated that ozone preconditioning improved renal inflammation and damage by blocking the activation of TLR4-NF- $\mathrm{KB}$ pathway in renal ischemia/ reperfusion injury. Also, ozone significantly reduced the mRNA level of TNF- $\alpha$, IL-1 $\beta$, IL-6, ICAM-1 (Intercellular Adhesion Molecule 1) and MCP-1 (monocyte chemoattractant protein 1) [24]. On the other hand, medical ozone, in vitro, has proven to be effective against viruses, bacteria, fungi and spores, destroying cells membrane and viruses envelop [25]. 


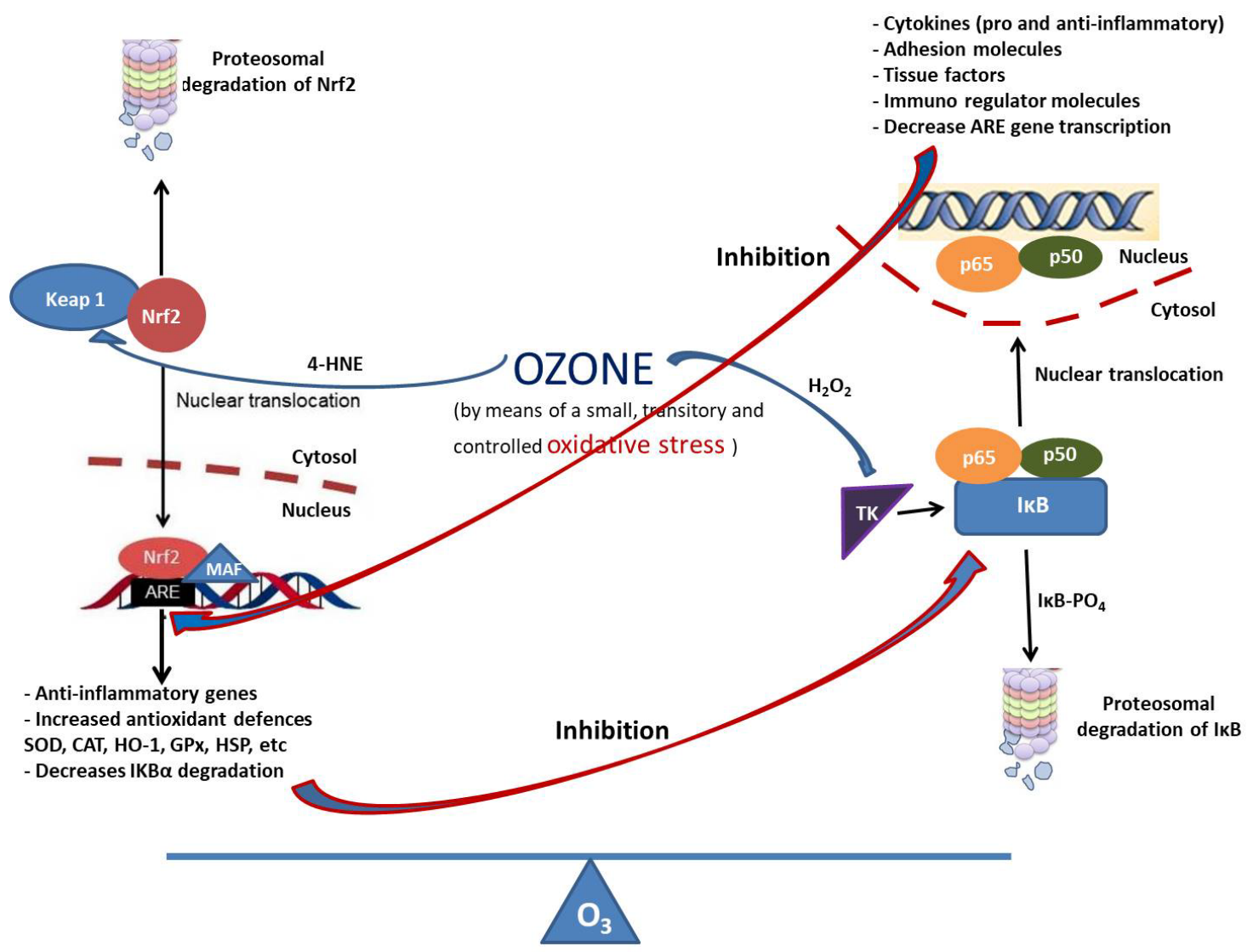

Figure 1: Ozone and its relation with Nrf2 and NF-kB.

Ozone, at therapeutic doses, is capable of producing a small, transitory and controlled oxidative stress. The nuclear transcription factor Nrf2 is usually present within the cytosol as a complex with Keap-1 protein. The 4-HNE (ozone active metabolite) binds to Cys 151 of Keap1 and suppresses the constitutive inhibition of Nrf2, which then translocates into the nucleus. After binding to Maf, Nrf2 binds to ARE and switches on the synthesis of highly cytoprotective enzymes (SOD, catalase, GSH, heme-oxygenase-1, HSP, etc) maintaining a redox balance. NF- $\mathrm{KB}$ is also a redoxregulated transcription factor, involved in inflammation, immune function, cellular growth and apoptosis. In resting, it exists in an inactive form complexed with the inhibitor I $\mathrm{B}$. In the presence of oxidative stress, $\mathrm{H}_{2} \mathrm{O}_{2}$ (ozone active metabolite) activates a tyrosine kinase that phosphorylates I $\mathrm{B}$ and causes its detachment from the inactive complex. The heterodimer moves promptly from the cytosol into the nucleus, where it regulates gene expression forming new proteins such as cytokines (IL-1, IL-2, IL-6, IL-10, TNF- $\alpha$ ), COX-2, iNOS, adhesion molecules (ICAM), tissue factor, immunoregulatory molecules. At the same time, these two pathways inhibit each other at their transcription level via protein-protein interactions or through secondary messenger effects [19]. Nrf2 opposes the transcriptional upregulation of proinflammatory cytokine genes. Nrf2 binds to the proximity of inflammatory cytokine genes, including IL-6 and IL-1 $\beta$, and inhibits their transcription.

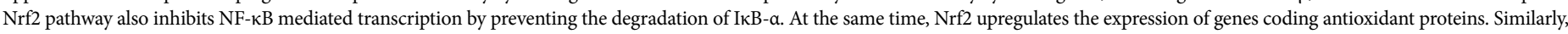
NF- $\mathrm{kB}$ mediated transcription reduces the Nrf2 activation by reducing the ARE gene transcription, among other factors. Therefore, it can be considered that ozone is involved in the balance between these two transcription factors.

Nrf2, nuclear factor erythroid 2-related factor 2;Keap1, Kelch-like erythroid cell-derived protein; Maf, musculoaponeuroticfibrosarcoma; ARE, antioxidant response element; HO-1, heme oxygenase-1; 4-HNE, 4-Hydroxynonenal; HSP, Heat shock protein; SOD, superoxide dismutase; GSH, reduced glutathione; $\mathrm{H}_{2} \mathrm{O}_{2}$, hydrogen peroxide; TNF, tumor necrosis factor; COX-2, cyclooxygenase-2; ICAM, intercellular adhesion molecule; iNOS, inducible nitric oxide synthase.

\section{Ozone Therapy and its Positive Effects in the Treatment of Patients with COVID-19}

Among the therapeutic effects of ozone therapy that favors the positive evolution of patients with COVID-19 are:

- Ozone improves oxygen metabolism increasing cellular oxygenation. Improving the hexose-monophosphate shunt, due to the activation of 2,3-DPG which, by binding to the $\beta$-chain of hemoglobin $(\mathrm{Hb})$, causes a shift to the right of the Hb dissociation curve. This enhances the release of oxygen in the hypoxic tissues. There is also an improvement of the glycolytic pathway on erythrocytes significantly increasing their ATP content $[11,13]$, recovering the elasticity of the red cell membrane thus improving blood rheology and capillarity [26]. There is a significant improvement in blood flow and oxygenation of ischemic tissues due to ozone treatment [27-30]. This is due to Nitric
Oxide (NO), S-nitrosothiols cooperating with Carbon Monoxide (CO) and released prostacyclin [31,32]. Different preclinical and clinical studies have demonstrated the effect of ozone in modulating the NO levels and its importance in the protection of the vascular endothelium cells [32-34].

- Ozone is capable of inducing the release and modulation of interferons and related cytokines. Also, stimulates antioxidant defense systems, counteracting the state of hyperinflammation, cytokine storm and oxidative stress, suffered by patients with COVID-19. This is achieved through the increase in Nrf2 factors and restoring cellular redox balance $[35,36]$. There is also the activation of heme oxygenase- 1 (HO-1) by increasing the release of $\mathrm{CO}$ and bilirubin. This contributes to reducing inflammation [37]. Several preclinical and clinical studies report a decrease in proinflammatory cytokines as IL-1, IL-6, TNFa, as well as ICAM-1, MCP-1, among others [24,38-45]. Ozone was able to 
modulate the phagocytic cells in peripheral blood and the mechanisms on how messengers can activate immunological response leading to the therapeutic biological effects $[46,47]$. This is a very positive effect on COVID-19 infection. The inflammatory response is a hallmark of severe SARS-CoV-2 infection, cytokine storm can lead to the death of these patients. The protective effect of ozone therapy was achieved by its anti-inflammatory property through the modulation of nucleotidebinding oligomerization domain-like receptor containing pyrin domain 3 (NLRP3) inflammasome, enhancing the antioxidant activity of Nrf2 and inhibiting apoptosis [48,49]. The NLRP3 inflammasome is a critical component of the innate immune system that mediates caspase- 1 activation and the secretion of proinflammatory cytokines IL-1 $\beta /$ IL-18 in response to microbial infection and cellular damage. On the other hand, activation of Toll-Like Receptor (for example TLR4) by SARS-CoV-2 causes a biochemical cascade that begins with the formation of pro-IL-1 cleaved by caspase-1 and followed by activation of the inflammasome. IL-1 is secreted outside the macrophage, mediating lung inflammation, fever and fibrosis, and provoking severe respiratory problems [50]. It has been demonstrated that ozone preconditioning protected the rat kidney from reperfusion injury via modulation of the TLR4-NF- $\mathrm{B}$ pathway [24].

- COVID-19 patients suffer from microthrombi due to increased viscosity and erythrocyte aggregation, among other factors. Ozone has an antiplatelet effect, increases some prostacyclins (like PGI2) leading to vasodilatation, as well as modulates antithrombin III [31,51]. All these effects, in conjunction with better blood circulation, can help to decrease the hypercoagulation phenomena present in these patients.

- Ozone can block the virus's ability to replicate by balancing the cellular redox state, through the control of Nrf2 [52,53]. SARS-CoV-2 cell entry depends on Angiotensin-Converting Enzyme 2 (ACE2) and Transmembrane protease, serine 2 (TMPRSS2). SARS spike protein $S$ will attach to ACE2. Following attachment to ACE2, viral entry requires $S$ protein priming, which is performed by TMPRSS2 cleaving $S$ protein. TMPRSS2 activity is essential for viral spread and pathogenesis in the infected host, and TMPRSS2 inhibitors have been investigated as a potential therapeutic target for SARS-CoV-2. Nrf2 activators have an important role in reducing viral pathogenesis via inhibiting virus entry through inhibit TRMPSS2 [54,55]. Nrf2 activators may offer multiple ways to regain control of important pathways to increase resistance and slow viral replication. Application of an NRF2 activating agent, ACE2 mRNA was down-regulated 3.5-fold and TMPRSS2 was down-regulated 2.8-fold in human liver-derived HepG2 cells [56]. Exacerbated lung injury in Nrf2-/- mice was associated with increased pulmonary expression of inflammatory cytokines (TNF- $\alpha$, IL-1 $\beta$, IL-6) and with decreased pulmonary antioxidant and detoxifying enzymes relative to Nrf2+/+ mice [57]. Furthermore, pretreatment with the Nrf2-ARE inducer sulforaphane significantly attenuated Respiratory Syncytial Virus (RSV)-induced bronchopulmonary inflammation, epithelial injury and pulmonary viral expression in $\mathrm{Nrf} 2+/+$ mice [58]. Results from the study confirmed an association of oxidative stress in RSV pathogenesis and provide compelling evidence for an important regulatory role of Nrf2-ARE as a host defense mechanism against RSV disease. Another study found an inverse relationship between the levels of Nrf2 expression and influenza A viral entry and replication within nasal epithelial cells [59]. In response to experimentally applied mechanical ventilation, greater levels of lung alveolar and vascular permeability and inflammatory responses were found in Nrf2-/- compared to Nrf2+/+ mice [60]. In mice, Nrf2 deficiency caused augmented ovalbumin-driven airway inflammation and hyperresponsiveness. In this study, the enhanced allergic response in Nrf2-/- mice was associated with more pronounced lung mucus cell hyperplasia, eosinophilic infiltration, increased Th2 cytokines IL-4 and IL-13 and suppressed multiple antioxidants relative to $\mathrm{Nrf2+/+}$ mice [61]. In an experimental sepsis model, Nrf2 deficiency increased the inflammation and mortality of mice against bacterial endotoxin (LPS)- and cecal ligation and puncture-induced septic shock [62]. This indicates that Nrf2 is a novel modifier of sepsis that determines survival by mounting an appropriate innate immune response. Data, therefore, suggest that Nrf2-ARE activators exert protective effects on LPS-induced inflammation, and suggested their potential therapeutic role for intervening sepsis syndrome. Taking into account that ozone stimulates Nrf2 $[28,36,37,63]$, this could be an important physiological mechanism to block endogenous COVID-19 reduplication by preventing contact with receptors of SARS-CoV-19 through downregulation of ACE2 and TMPRSS2, inactivating the ability of the virus to enter cells [55]. The re-equilibration of the cellular REDOX state achieved with the ozone therapy is also important in the induction of cytokines synthesis in monocytes and lymphocytes and in the release of HO- 1 and heat shock proteins which are potent activators of the immune system $[12,64]$.

\section{Conclusion}

In summary, the positive aspect of ozone therapy is the ability to activate several defense mechanisms that cooperate to regain a normal redox system and a modulation of the NFkB/Nrf2 pathway. Today, ozone therapy represents the most practical approach for integrating standard therapies to achieve homeostasis. Therefore, due to the ozone therapeutical effects, it can be proposed as an adjunct therapy in SARSCoV-2. Three randomized control trials (NCT04359303, NCT04370223 and NCT04444531) are pending classification and approval to start in Spain, one in Iran (IRCT20190618043923N4) and two more (NCT04366089 and NCT04388514) started in Italy one month ago.

\section{Highlights}

Ozone Therapy can be used for the treatment of COVID-19.

Ozone can achieve an equilibrium between Nrf2 and NF- $\mathrm{kB}$, modulating oxidative stress and pro-inflammatory cytokines.

Ozone counteracts hyperinflammation, cytokine storm and oxidative stress.

Ozone improves oxygen metabolism, blood flow and oxygenation of ischemic tissues.

\section{Author Contributions}

SMC - works on the conceptualization, drafting, editing and revision. JAMM, AHM, FJHT and JBN - work on the conceptualization and critical review of the manuscript. All authors have approved the final version of the manuscript 


\section{Conflict of Interest}

The authors declare they have no conflict of interest.

\section{References}

1. Li Q, Guan X, Wu P, Wang X, Lei Zhou, et al. (2020) Early Transmission Dynamics in Wuhan, China, of Novel Coronavirus-Infected Pneumonia. N Engl J Med 382: 11991207. [crossref]

2. Huang C, Wang Y, Li X, Ren L, Jianping Zhao, et al. (2020) Clinical features of patients infected with 2019 novel coronavirus in Wuhan, China. Lancet 395: 497-506. [crossref]

3. WHO (2020) Clinical management of severe acute respiratory infection when Novel coronavirus (2019-nCoV) infection is suspected: Interim Guidance. Available: $\mathrm{WHO} / \mathrm{nCoV} / \mathrm{Clinical} / 2020.2$.

4. Chen Y, Liu Q, Guo D (2020) Emerging coronaviruses: Genome structure, replication, and pathogenesis. J Med Virol 92: 418-423. [crossref]

5. Prieto-Pérez L, Fortes J, Soto C, Vidal-González A (2020) Histiocytic hyperplasia with hemophagocytosis and acute alveolar damage in COVID-19 infection. Mod Pathol.

6. Bracaglia C, Prencipe G, De Benedetti F (2017) Macrophage Activation Syndrome: different mechanisms leading to a one clinical syndrome. Pediatr Rheumatol Online J 15: 5. [crossref]

7. Ruiz-Irastorza G, Crowther M, Branch W, Khamashta MA (2010) Antiphospholipid syndrome. Lancet 376: 1498-509. [crossref]

8. Menéndez S, González R, Ledea OE, Hernández F (2008) Ozono: Aspectos Básicos y Aplicaciones clínicas. 1ra Ed. La Habana, Cuba: Editorial CENIC 10-320.

9. Jacobs, MT (1982) Investigation into pitfalls and typical complications in ozoneoxygen therapy. Untersuchung uber Zwischenfalle und typische Komplikationen in der Ozon Sauerstoff-Therapie. OzoNachrichten 1: 5.

10. León OS, Menéndez S, Merino N, Castillo R, S Sam, et al. (1998) Ozone oxidative preconditioning: a protection against cellular damage by free radicals. Med Inflamm 7: 289-294. [crossref]

11. Bocci V (2005) Ozone - A new medical drug. Dordrecht, The Netherlands. Springer 1-295.

12. Bocci V, Zanardi I, Valacchi G, Borrelli E, Valter Travagli (2015) Validity of OxygenOzone Therapy as Integrated Medication form in Chronic Inflammatory Diseases. Cardiovasc Hematol Disord Drug Targets 15: 127-138. [crossref]

13. Sagai M, Bocci V (2011) Mechanisms of action involved in ozone therapy: is healing induced via a mild oxidative stress? Med Gas Res 1: 29. [crossref]

14. Hernández F, Calunga JL, Turrent J, Menéndez S, Adonis Montenegro Perdomo (2005) Ozone therapy effects on blood biomarkers and lung function of asthma patients. Arch Med Res 36: 549-554. [crossref]

15. Borrelli E, Bocci V (2014) Oxygen ozone therapy in the treatment of chronic obstructive pulmonary disease: An integrative approach. Am J Clin Exp Med 2: 9-13.

16. Calunga-Fernández JL, Paz-Agüero Y, Menéndez-Cepero S, Martínez-Aparicio A (2011) La ozonoterapia en pacientes con enfisema pulmonar. Revista Médica de Chile 139: 439-447.

17. León-Fernández OS, Viebahn R, López-Cabreja G, Serrano-Espinosa I, Yanet Hernández Matos, et al. (2016) Medical ozone increases methotrexate clinical response and improves cellular redox balance in patients with rheumatoid arthritis. Eur J Pharmacol 789: 313-318. [crossref]

18. Oru GT, Viebhan R, Cabreja GL, Espinosa IS (2017) Medical Ozone Reduces the Risk of $\gamma$-Glutamyl Transferase and Alkaline Phosphatase Abnormalities and Oxidative Stress in Rheumatoid Arthritis Patients Treated with Methotrexate. SM J Arthritis Res 1: 1004 .

19. Kobayashi EH, Suzuki T, Funayama R, Nagashima T, Makiko Hayashi, et al. (2016) Nrf2 suppresses macrophage inflammatory response by blocking proinflammatory cytokine transcription. NatCommun 7: 11624. [crossref]

20. Galiè M, Covi V, Tabaracc Gi, Malatesta M (2019) The Role of Nrf2 in the Antioxidant Cellular Response to Medical Ozone Exposure. Int J Mol Sci 20: 4009. [crossref]

21. León OS, Ajamieh HH, Berlanga J, Menéndez S, Renate Viebahn-Hánsler, et al.
(2008) Ozone oxidative preconditioning is mediated by Al adenosine receptors in a rat model of liver ischemia/reperfusion. Transpl Int 21: 39-48. [crossref]

22. Mohan S, Gupta D (2018) Crosstalk of toll-like receptors signaling and Nrf2 pathway for regulation of inflammation. Biomed Pharmacother 108: 1866-1878. [crossref]

23. Iwasaki A, Medzhitov R (2004) Toll-like receptor control of the adaptive immune responses. Nat Immunol 5: 987-995. [crossref]

24. Xing $\mathrm{B}$, Chen $\mathrm{H}$, Wang $\mathrm{L}$, Weng $\mathrm{X}$, et al. Ozone oxidative preconditioning protects the rat kidney from reperfusion injury via modulation of the TLR4-NF- $\kappa B$ pathway. Acta Cirúrgica Brasileira 30

25. Ohmine $S$ (2005) Investigation of the mechanisms of ozone-mediated viral inactivation (2005). Theses and Dissertations 597. Available: https://scholarsarchive. byu.edu/etd/597.

26. Giunta R, Coppola A, Luongo C, Sammartino A, S Guastafierro, et al. (2001) Ozonized autohemotransfusion improves hemorheological parameters and oxygen delivery to tissues in patients with peripheral occlusive arterial disease. Ann Hematol 80: 745-748. [crossref]

27. Ajamieh HH, Berlanga J, Merino N, Martínez Sánchez G, Anna M Carmona, et al. (2005) Role of protein synthesis in the protection conferred by ozone oxidative preconditioning in hepatic ischemia/reperfusion. Transpl Int 18: 604-612. [crossref]

28. Meng W, Xu Y, Li D, Zhu E, Li Deng, et al. (2017) Ozone protects rat heart against ischemia-reperfusion injury: A role for oxidative preconditioning in attenuating mitochondrial injury. Biomed Pharmacother 88: 1090-1097. [crossref]

29. Wang L, Chen H, Liu XH, Chen ZY, Xiao-Dong Weng, et al. (2014) Ozone oxidative preconditioning inhibits renal fibrosis induced by ischemia and reperfusion injury in rats. Exp Ther Med 8: 1764-1768. [crossref]

30. Wu XN, Zhang T, Wang J, Liu X, Zhen-sheng Li, et al. (2016) Magnetic resonance diffusion tensor imaging following major ozonated autohemotherapy for treatment of acute cerebral infarction. Neural Regen Res 11: 1115-1121. [crossref]

31. Schulz S, Ninke S, Watzer B, Nusing RM (2012) Ozone induces synthesis of systemic prostacyclin by cyclooxygenase- 2 dependent mechanism in vivo. BiochemlPharmacol 83: 506-513. [crossref]

32. Ajamieh HH, Menéndez S, Martínez-Sánchez G, Candelario-Jalil E et al. (2004) Nitric oxide and their role in the oxidative preconditioning in hepatic ischemiareperfusion. Liver Int 24: 55-62.

33. Al-Dalain M, Martínez G, Candelario-Jalil E, Menéndez S, et al. (2001) Ozone treatment reduces markers of oxidative and endothelial damage in an experimental diabetes model in rats. Pharmacol Res 44: 391-396. [crossref]

34. Martínez G, Al-Dalain SM, Menéndez S, Re L, et al. (2005) Therapeutic efficacy of ozone medical treatments in patients with diabetic foot. Eur J Pharmacol 523: 151161. [crossref]

35. Bocci V, Valacchi G (2015) Nrf2 activation as target to implement therapeutic treatments. Front Chem 3.

36. Re L, Martinez-Sanchez G, Bordicchia M, MalcangiG, et al. (2014) Is ozone preconditioning effect linked to Nrf2/EpRE activation pathway in vivo? A preliminary result. Eur J Pharmacol 742: 158-162. [crossref]

37. Pecorelli A, Bocci V, Acquaviva A, Belmonte G, et al. (2013) NRF2 activation is involved in ozonated human serum upregulation of HO-1 in endothelial cells. ToxicolApplPharmacol 267: 30-40. [crossref]

38. Zamora Z, Borrego A, López O, Delgado R, et al. (2005) Effects of ozone oxidative preconditioning on TNF- $\alpha$ release and antioxidant-prooxidant intracellular balance in mice during endotoxic shock. MediatInflamm 1: 16-22.

39. Bette M, Nüsing RM, Mutters R, Zamora ZB, et al. (2006) Efficiency of Tazobactam/ Piperacillin in lethal peritonitis is enhanced after pre-conditioning of rats with O3/ O2-pneumoperitoneum. Shock 25: 23-29. [crossref]

40. Dranguet J, Fraga A, Díaz MT, Mallok A, et al. (2013) Ozone oxidative postconditioning ameliorates joint damage and decreases pro-inflammatory cytokine levels and oxidative stress in PG/PS-induced arthritis in rats. Eur J Pharmacol 714: 318-324. [crossref]

41. Chang JDS, Lu HS, Chang YF, Wang D (2005) Ameliorative effect of ozone on cytokine production in mice injected with human rheumatoid arthritis synovial fibroblast cells. Rheumatolint 26: 142-151. [crossref] 
42. Aslaner A, Çakır T, Çelik B, Doğan U, et al. (2015) Does intraperitoneal medical ozone preconditioning and treatment ameliorate the methotrexate induced nephrotoxicity in rats? Int J ClinExp Med 8: 13811-13817.

43. Xie TY, Yan W, Lou J, Chen XY (2016) Effect of ozone on vascular endothelial growth factor (VEGF) and related inflammatory cytokines in rats with diabetic retinopathy. GenetMol Res 15: 15027558. [crossref]

44. Delgado-Roche L, Riera-Romo M, Mestab F, Hernández-Matos Y, et al. (2017) Medical ozone promotes $\mathrm{Nrf2}$ phosphorylation reducing oxidative stress and pro-inflammatory cytokines in multiple sclerosis patients. Eur J Pharmacol 811: 148-154. [crossref]

45. Calunga-Fernández JL, Menéndez-Cepero S, Zamora-Rodríguez Z (2019) Ozone Therapy in rats submitted to subtotal nephrectomy: Role of interleukin 6 and antioxidant system. Revista Cubana de Investigaciones Biomédicas 38.

46. Diaz-Luis J, Menendez-Cepero S, Diaz-Luis A, Ascanio Garcia Y (2015) In vitro effectof ozone in phagocyticfunctionofleucocytes in peripheralblood. JO3T 1: 1-9.

47. Díaz-Luis J, Menéndez-Cepero S, Macías-Abraham C, Fariñas-Rodríguez L (2018) Systemic ozone therapy by rectal insufflation for immunoglobulin A deficiency. MSMEDICC Review 20: 29-35.

48. Wang Z, Zhang A, Meng W, Wang T, et al. (2018) Ozone protects the rat lung from ischemia-reperfusion injury by attenuating NLRP3-mediated inflammation, enhancing Nrf2 antioxidant activity and inhibiting apoptosis. Eur J Pharmacol 835: 82-93. [crossref]

49. Yu G, Bai Z, Chen Z, Chen H, et al. (2017)The NLRP3 inflammasome is a potential target of ozone therapy aiming to ease chronic renal inflammation in chronic kidney disease. IntImmunopharmacol 43: 203-209. [crossref]

50. Conti P, Ronconi G, Caraffa A, Gallenga CE, et al. (2020) Induction of proinflammatory cytokines (IL-1 and IL-6) and lung inflammation by COVID-19: Anti-inflammatory strategies. J BiolRegulHomeostAgents 34: 1. [crossref]

51. Martínez Y,Zamora Z, González R, Guanche D (2010) Efecto del precondicionamiento oxidativo con ozono en el tiempo de sangrado y formación de trombo venoso en un modelo de choque séptico en ratas. Revista CENIC. Ciencias Biológicas 41.

52. Ricevuti G, Franzini M, Valdenassi L (2020) Oxygen-ozone immunoceutical therapy in COVID-19 outbreak: facts and figures. Ozone Therapy 5.
53. Hernández A, Viñals M, Isidoro T, Vilás F (2020) Potential Role of Oxygen-Ozone Therapy in Treatment of COVID-19 Pneumonia. Am J Case Rep 21: 925849.

54. Hoffmann M, Kleine-Weber H, Schroeder S, Krüger N, et al. (2020) SARS-CoV-2 Cell entry depends on ACE2 and TMPRSS2 and is blocked by a clinically proven protease inhibitor. Cell 181: 271-280. [crossref]

55. Hassan SM, Jawad MJ, Ahjel SW, Singh RB, et al. (2020) The Nrf2 activator (DMF) and Covid-19: Is there a possible role? Med Arch 74: 134-138. [crossref]

56. McCord JM, Hybertson BM, Cota-Gomez A, Gao B (2020) Nrf2 activator PB125 as a potential therapeutic agent against COVID-19. bioRxiv.

57. Cho HY, Kleeberger SR (2010) Nrf2 protects against airway disorders. ToxicolApplPharmacol 244: 43-56. [crossref]

58. ChoHY, Imani F, Miller-DeGraff L, Walters D, et al. (2009) Antiviral activity of Nrf2 in a murine model of respiratory syncytial virus disease. Am J Respir Crit Care Med 179: 138-150. [crossref]

59. Kesic MJ, Simmons SO, Bauer R, Jaspers I (2011) Nrf2 expression modifies influenza A entry and replication in nasal epithelial cells. Free RadicBiol Med 51: 444-453. [crossref]

60. Papaiahgari S, Yerrapureddy A, ReddySR, Reddy NM, et al. (2007) Genetic and pharmacologic evidence links oxidative stress to ventilator-induced lung injury in mice. AmJRespirCritCare Med 176: 1222-1235. [crossref]

61. Rangasamy T, Guo J, Mitzner WA, Roman J, et al. (2005) Disruption of Nrf2 enhances susceptibility to severe airway inflammation and asthma in mice. J Exp Med 202: 47-59. [crossref]

62. Thimmulappa RK, Lee H, Rangasamy T, Reddy SP, et al. (2006) Nrf2 is a critical regulator of the innate immune response and survival during experimental sepsis. JClinInvest 116: 984-995. [crossref]

63. Siniscalco D, Trotta MC, Brigida AL, Maisto R, et al. (2018) Intraperitoneal administration of oxygen/ozone to rats reduces the pancreatic damage induced by streptozotocin. Biology 7: 10-22. [crossref]

64. Bocci V, Aldinucci C, Mosci F, Carraro F, et al. (2007) Ozonation of human blood induces a remarkable upregulation of heme oxygenase- 1 and heat stress protein-70. Mediators Inflamm 267-85.

\section{Citation:}

Menendez-Cepero S, Marques-Magallanes-Regojo JA, Hernandez-Martinez A, Hidalgo Tallón FJ, Baeza-Noci J (2020) Therapeutic Effects of Ozone Therapy that Justifies Its Use for the Treatment of COVID-19. J Neurol Neurocrit Care Volume 3(1): 1-6. 